\title{
Dose-Dependent Antimicrobial Activity of Silver Nanoparticles on Polycaprolactone Fibers against Gram-Positive and Gram-Negative Bacteria
}

\author{
Erick Pazos-Ortiz, Jose Hafid Roque-Ruiz, Efrén Amador Hinojos-Márquez, \\ Juan López-Esparza, Alejandro Donohué-Cornejo, Juan Carlos Cuevas-González, \\ León Francisco Espinosa-Cristóbal, and Simón Yobanny Reyes-López
}

Instituto de Ciencias Biomédicas, Universidad Autónoma de Ciudad Juárez, Envolvente del PRONAF y Estocolmo s/n, 32300 Ciudad Juárez, CHIH, Mexico

Correspondence should be addressed to Simón Yobanny Reyes-López; simon.reyes@uacj.mx

Received 1 June 2017; Accepted 6 September 2017; Published 6 November 2017

Academic Editor: Bo Tan

Copyright (C) 2017 Erick Pazos-Ortiz et al. This is an open access article distributed under the Creative Commons Attribution License, which permits unrestricted use, distribution, and reproduction in any medium, provided the original work is properly cited.

\begin{abstract}
The adhesion ability and adaptability of bacteria, coupled with constant use of the same bactericides, have made the increase in the diversity of treatments against infections necessary. Nanotechnology has played an important role in the search for new ways to prevent and treat infections, including the use of metallic nanoparticles with antibacterial properties. In this study, we worked on the design of a composite of silver nanoparticles (AgNPS) embedded in poly-epsilon-caprolactone nanofibers and evaluated its antimicrobial properties against various Gram-positive and Gram-negative microorganisms associated with drug-resistant infections. Polycaprolactone-silver composites (PCL-AgNPs) were prepared in two steps. The first step consisted in the reduction in situ of $\mathrm{Ag}^{+}$ions using $\mathrm{N}, \mathrm{N}$-dimethylformamide (DMF) in tetrahydrofuran (THF) solution, and the second step involved the simple addition of polycaprolactone before electrospinning process. Antibacterial activity of PCL-AgNPs nanofibers against $E$. coli, S. mutans, K. pneumoniae, S. aureus, P. aeruginosa, and B. subtilis was evaluated. Results showed sensibility of E. coli, K. pneumoniae, S. aureus, and P. aeruginosa, but not for B. subtilis and S. mutans. This antimicrobial activity of PCL-AgNPs showed significant positive correlations associated with the dose-dependent effect. The antibacterial property of the PCL/Ag nanofibers might have high potential medical applications in drug-resistant infections.
\end{abstract}

\section{Introduction}

At present, bacteria have acquired the ability to adapt to stress conditions and developed various mechanisms of resistance due to excessive use of antibiotics, which makes them a serious health problem. Consequently, there is a need to develop new bactericidal materials [1]. Escherichia coli (E. coli) and Staphylococcus aureus (S. aureus) are two of the most common bacteria that have shown important antibioticresistance effects, producing serious intestinal, skin, and other soft tissue infections including pneumonia, endocarditis, and septicemia. Other types of bacteria commonly found in important nosocomial infections are Pseudomonas aeruginosa (P. aeruginosa), Streptococcus pyogenes (S. pyogenes), and Klebsiella pneumonia (K. pneumonia), which have also developed high drug resistance to antibiotics therapies. Thus, attention is drawn to treatment guidelines and the use of novel antimicrobial agents with better bactericidal properties [2]. In this situation, nanotechnology has focused on the development of nanomaterials with the ability to interact with biological entities that are pathogenic to humans. Among these, synthesis of metal nanoparticles has attracted scientific interest, because of the bactericidal properties shown by metals like gold, copper, and silver which demonstrated very interesting antimicrobial properties [3]. The antimicrobial activity of silver was described since antiquity and nanoscale silver has been proven as a powerful bactericidal agent because of its ability to cross biological membranes, 
so it is used for controlling bacteria in dental therapies, catheters, burns, wounds, and others [4]. However, silver nanoparticles (AgNPs) turn out to be toxic to human cells at concentrations above $1 \%$ and in long treatments lead to accumulation in the organism causing the disease called argyria (bluish discoloration of skin). Therefore, it is necessary to elaborate materials with low concentrations of silver nanoparticles, in order to obtain a bactericidal effect without being cytotoxic [5]. Administration of AgNPs as bactericidal treatment needs a vehicle; polymeric matrices are the most widely used materials for this purpose. Attachment of metal nanoparticles to the polymeric matrix has been demonstrated to improve physical, chemical, and mechanical properties of polymers and bactericidal properties of nanoparticles. Poly- $\varepsilon$-caprolactone (PCL) is a biodegradable, biocompatible, bioresorbable, and nontoxic polymer widely used in the biomedical area, tissue engineering, skin regeneration, scaffolding support for fibroblasts, and growth of osteoblasts in systems of continuous bone repair [6]. Pharmaceutical industry uses polymer matrices as delivering systems for active principles. This methodology allows the fabrication of membranes for biomedical use as biological tissue regeneration for dressings, environmental remediation, and water treatment $[2,7,8]$. Although it has been reported previously in scientific literature, studies about synthesis, characterization, and antimicrobial activity of PCL nanofibers by electrospinning containing AgNPs against Gram-negative and Gram-positive bacterial strains, including multidrug resistant microorganisms, are necessary. Furthermore, it is recommended to redesign novel and easy routes for the preparation of PCL-AgNPs nanofibers and evaluate its antimicrobial activity involving a large variety of microorganisms that can offer a better understanding of bacterial inhibition capacity for drug-resistant infections [2]. The objective of this contribution was to prepare PCL nanofibers containing AgNPs and evaluate their antimicrobial activity on several microorganisms considered as drug-resistant bacteria by minimum inhibitory concentration (MIC) method.

\section{Methodology or Experimental Section}

2.1. Materials. All the chemicals used were of analytical grade. High purity water was employed. Silver, nitrate $\left(\mathrm{AgNO}_{3}\right)$, poly- $\varepsilon$-caprolactone with an average molecular weight (Mw) of 80,000 , N,N-dimethylformamide (DMF) $(\geq 98)$, and tetrahydrofuran $(\geq 99.5 \%)$ were purchased from Aldrich. All chemical reagents were used as received. Müller-Hinton agar plates were used for antibiogram test. Escherichia coli (ATCC 25922 $2^{\mathrm{TM}}$ ), Streptococcus mutans (ATCC $19615^{\mathrm{TM}}$ ), Klebsiella pneumoniae (ATCC $13883^{\mathrm{TM}}$ ), Staphylococcus aureus (ATCC 25923 ${ }^{\mathrm{TM}}$ ), Pseudomonas aeruginosa (ATCC $27853^{\mathrm{TM}}$ ), and Bacillus subtilis (ATCC $19163^{\mathrm{TM}}$ ) microorganisms were obtained from American Type Culture Collection.

2.2. Silver Nanoparticles Preparation. The synthesis of AgNPs was carried out in one step. To a solution with ratio of $7: 3$ of dimethylformamide (DMF) and tetrahydrofuran (THF), respectively, silver nitrate $\left(\mathrm{AgNO}_{3}\right)$ was added as a precursor agent. The solution was placed under magnetic stirring to observe a color change to light yellow. Particle size was controlled by the initial concentrations of silver nitrate $(0 \mathrm{mM}$, $1 \mathrm{mM}, 10 \mathrm{mM}, 50 \mathrm{mM}$, and $100 \mathrm{mM}$ ), according to previous studies [2]. UV-Vis absorption spectra were measured at room temperature in a Cary 100 spectrophotometer (Varian Corp.) with a variable wavelength within 100-900 nm using a $10 \mathrm{~mm}$ quartz cell. Particle size and distribution were measured in an HORIBA SZ-100 Nanoparticle Analyzer with dynamic light scattering (DLS) technology.

2.3. Preparation and Fabrication of Nanofibers Scaffolds. The second step was the preparation of nanofibers by electrospinning; the simple method consisted in forming a viscous solution of PCL to $10 \%$ with the initial silver nitrate solutions (0 mM, $1 \mathrm{mM}, 10 \mathrm{mM}, 50 \mathrm{mM}$, and $100 \mathrm{mM}$ ) under magnetic stirring at room temperature. The resulting viscous solution of PCL with silver nanoparticles was loaded into a syringe connected to a stainless steel needle of $1.25 \mathrm{~mm}$ inner diameter. The steel needle was connected to a high-voltage generator, and an aluminum foil served as the counterelectrode. A dense web of fibers was collected on the aluminum foil. The used electrical potential amounted to $13 \mathrm{kV}$, the distance between the capillary and the substrate electrode was $15 \mathrm{~cm}$, and the feeding rate of the solution in syringe pump was $8 \mu \mathrm{L} / \mathrm{min}$. The electrospinning assay was performed at $22^{\circ} \mathrm{C}$.

2.4. Characterization of the Scaffolds. The morphologies of the PCL-Ag nanocomposites collected on carbon-coated copper grids were observed with a scanning electron microscopy (SEM, JEOLJSM-6400) operated at $20 \mathrm{kV}$. Before observation, the scaffolds were coated with platinum using a sputter coating. Fiber diameter was measured from the SEM micrographs. FTIR spectra were taken with an Alpha PlatinumATR spectrometer and transmission spectra of the samples were obtained by forming fiber films.

2.5. Antibacterial Activity. The antibacterial activities of PCLAgNPs nanofiber scaffolds were measured by disc diffusion method. Six different microbial species, E. coli, S. mutans, K. pneumoniae, $S$. aureus, $P$. aeruginosa, and B. subtilis, were cultured in Müller-Hinton broth by $20 \mathrm{~h}$ at $37^{\circ} \mathrm{C}$ before the test. $100 \mu \mathrm{L}$ of standardized suspensions for each bacterium, according to McFarland scale $\left(1.3 \times 10^{6} \mathrm{CFU} / \mathrm{mL}\right)$, was placed on Müller-Hinton agar plates. Disc shape samples of PCLAgNPs hybrid nanofiber scaffolds with $1 \times 1 \mathrm{~cm}^{2}$ dimension were prepared and subjected to the inhibition zone tests. The discs were sterilized with ultraviolet light for 2 hours and subsequently placed on E. coli, S. mutans, K. pneumoniae, $S$. aureus, $P$. aeruginosa, and $B$. subtilis culture plates. The agar plates were incubated for 24 hours at $37^{\circ} \mathrm{C}$. The relative antibacterial effect was found by measuring the clear zones of inhibition formed around the discs using a Vernier caliper instrument. The antimicrobial test for all microorganisms and nanofibers was made in triplicate.

2.6. Determining the Minimum Inhibitory Concentration. MIC was determined using the microbroth dilution method 
TABLE 1: AgNPs/PCL nanofiber diameters.

\begin{tabular}{lcc}
\hline Nanofibers with AgNPs & Diameter $(\mathrm{nm})$ & DE $(\mathrm{nm})$ \\
\hline PCL & 763 & 114 \\
PCL/Ag $12.5 \mathrm{mM}$ & 708 & 105 \\
PCL/Ag $25 \mathrm{mM}$ & 664 & 93 \\
PCL/Ag $50 \mathrm{mM}$ & 612 & 98 \\
PCL/Ag 100 mM & 559 & 94 \\
\hline
\end{tabular}

$\mathrm{DE}=$ standard deviation.

in 90 tubes. In each tube, one Sensi-Disc with diameter $16 \mathrm{~mm}$ containing concentrations of $0 \mathrm{mM}, 12.5 \mathrm{mM}, 25 \mathrm{mM}$, $50 \mathrm{mM}$, and $100 \mathrm{mM}$ of fiber PCL-AgNPs was placed. The tubes were incubated at $37^{\circ} \mathrm{C}$ for 24 hours. After that time, absorbance of each tube was measured. The antimicrobial test for all microorganisms and nanofibers was made in triplicate. The lowest concentration of scaffolds at which no turbidity was seen was regarded as the MIC.

\section{Results and Discussion}

DLS results showed uniform and well-distributed AgNPs in a range of 10-15 nm. Initial formation of AgNPs was visualized from color changes in the solutions, from colorless to light yellow. UV-Vis analysis exhibited well-defined plasmon band absorption at 415 and $440 \mathrm{~nm}$ for $\mathrm{Ag} 1$ to $10 \mathrm{mM}$ and 50 to $100 \mathrm{mM}$; at higher concentration of silver, color changed from pale yellow to dark brown, as reported previously [2]. On the other hand, the initial amounts of Ag nitrate and reducing agents left no residue and the reaction was assumed to be complete. This assertion was consistent with UV-vis spectroscopy in the wavelength range of 200-300 nm, where no residues of $\mathrm{Ag}^{+}$could be detected.

SEM images (Figure 1) show that the obtained fibers present a cylindrical smooth surface and free area of beads, precipitates, and fractures. It is evident from the SEM images of PCL-AgNPs nanofibers scaffolds that the electrospun nanofibers were smooth and uniform with optimized electrospinning parameters. Table 1 shows the average of the PCL and PCL-AgNPs nanofibers. The diameters of these nanofibers were observed to decrease upon an increment in the content of the AgNPs. Due to the presence of AgNPs in the solution, electrical charge and conductivity increased, which resulted in a thinner diameter of the fibers. Fibers formation was controlled by voltage, since it elongates and breaks surface tension of polymer solution. Increasing silver concentration caused instability of Taylor cone and an increase in fibers whipping movement.

Figure 1(e) shows STEM micrographs of the PCL-AgNPs. The AgNPs can be observed on the surface of the fibers with round shape, which is mainly distributed from 80 to $190 \mathrm{~nm}$ into the fibers, according to previous data reported [2]. The addition polymer promotes the formation of agglomerates (in dark) because of the change of polarity in the precursor solution. EDX spectrum in the all zone demonstrates that fibers composition consists of carbon, oxygen, and silver. EDX analysis, as a result, provides direct evidence that
AgNPs are embedded in the nanofibers. Results obtained by electron microscopy showed the existing relation between size distribution and morphology of silver nanoparticles. Dispersion and size are among the most important properties of composites with biomedical applications. Therefore, this work focused on obtaining fibers with small diameter and great uniformity, so they could act as a mechanism for delivering AgNPs.

3.1. Antibacterial Properties of PCL-AgNPs Nanofibers Composite. The current PCL-AgNPs hybrid nanofiber scaffolds were prepared with the aim of introducing antibacterial activities into the PCL electrospun nanofiber to enhance their applicability in medical field. The agar diffusion method showed the sensitivity of bacteria against the nanofibers with Sensi-Discs at different concentrations of AgNPs, taking the pure PCL nanofiber as control. Figure 2 illustrates the comparative results of antibacterial activities of PCL and PCL-AgNPs hybrid nanofibers. For S. aureus, E. coli, K. pneumoniae, and $P$. aeruginosa, inhibition halo was directly proportional to the AgNPs concentration. Furthermore, the main bacteria associated with multidrug-resistance infections were analyzed according their microbiological characteristics from cell membrane. Gram-negative bacteria (E. coli, $P$. aeruginosa, and K. pneumoniae) were found, in general, more sensitive to PCL-AgNPs nanofibers compared to Grampositive strains ( $S$. aureus, S. mutans, and B. subtilis). Figure 2 represents a selective mechanism of PCL-AgNPs nanofibers that depends on the Ag concentration and the type of cell membrane structure according to microbiological properties from specific bacterial strain.

Gram-negative bacteria showed the best inhibition results using PCL-AgNPs nanofiber scaffolds; therefore, the effectiveness of these materials against three bacteria was demonstrated. The Gram-negative bacteria present a cell wall composed of an inner thin peptidoglycan layer and an outer layer of liposaccharides. The scarce thickness of the cell wall increases the susceptibility of these bacteria to silver ions released by nanoparticles on the composite. By contrast, previous studies report that Gram-positive bacteria are resistant to silver ions. These bacteria resist exposure to silver ions due to their cell wall with a thick peptidoglycan layer composed of teicoic acids, which limits the uptake of silver nanoparticles. However, specific response of each bacterium depended on their metabolic characteristics. E. coli, $P$. aeruginosa, and K. pneumoniae are Gram-negative bacteria and their membranes present negative electrostatic charges, which attract and facilitate diffusion of AgNPs.

The mechanism of antibacterial action by Ag nanoparticles is not understood accurately. However, previous studies have demonstrated the crucial role of electrostatic attraction between bacterial cells (negative) and nanoparticles (positive). Previous researches using E. coli strains have demonstrated that silver nanoparticles permeate through the membrane easily and interact with protein synthesis, causing structural changes and death [9].

The general MIC found for the most PCL nanofibers containing AgNP was $12.5 \mathrm{mM}$. According to average of inhibition halo, the most sensitive bacteria to the PCL/Ag 


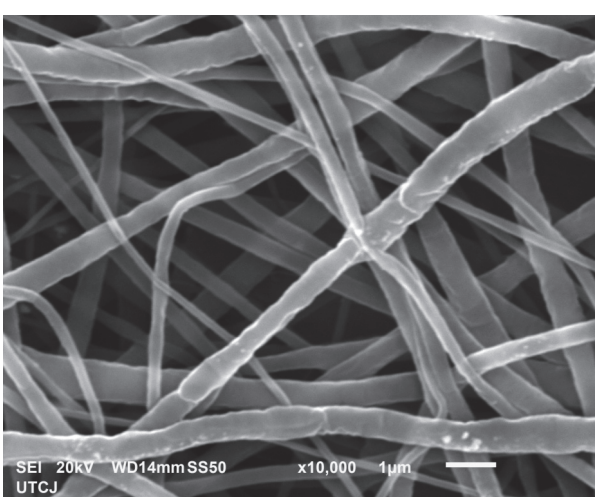

(a)

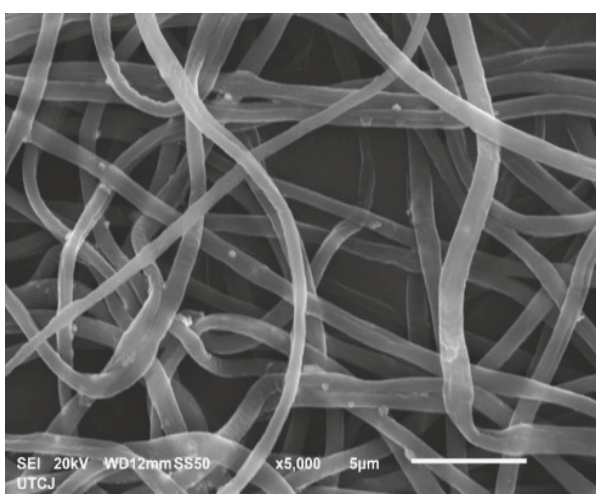

(c)

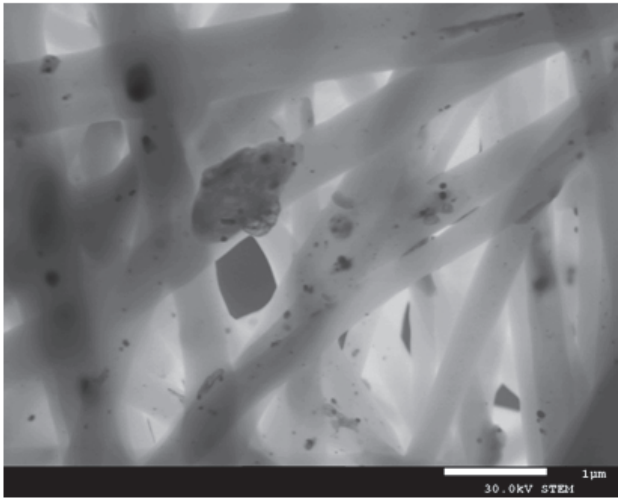

(e)

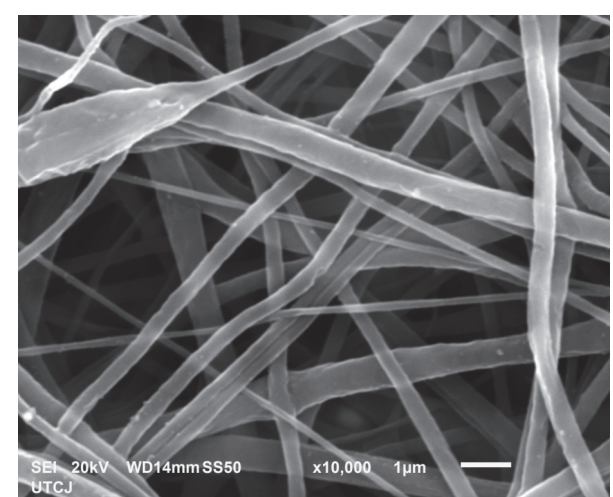

(b)

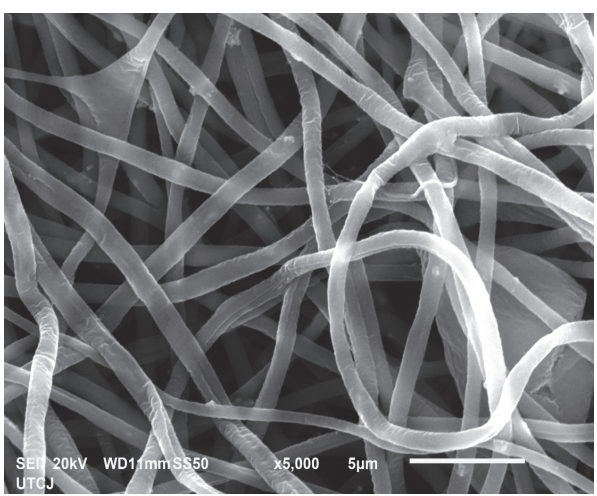

(d)

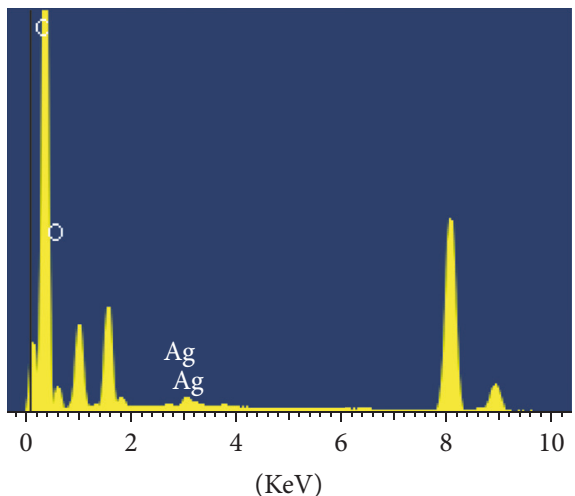

(f)

FIGURE 1: Images of PCL/Ag electrospun fibers from solution (a) $12.5 \mathrm{mM}$, (b) $25.0 \mathrm{mM}$, (c) $50 \mathrm{mM}$, and (d) $100 \mathrm{mM}$, (e) STEM image of PCL/Ag fibers, and (f) EDX analysis of PCL/Ag fibers.

nanofibers at any Ag concentration (12.5-100 mM) was $P$. aeruginosa $(34.25 \pm 10.2 \mathrm{~mm})$, followed by E. coli $(32.45 \pm$ $9.6 \mathrm{~mm})$, K. pneumoniae $(31.15 \pm 7.8 \mathrm{~mm})$, and $S$. aureus $(29.1$ $\pm 7.8 \mathrm{~mm}$ ); finally, the most resistant microorganisms were S. mutans and B. subtilis in which no inhibition halo was generated.

Through nonparametric statistical data analysis by Kruskal-Wallis (Table 2) and using the inhibition halos as response variable, it was noted that beginning from the $12.5 \mathrm{mM}$ AgNPs concentration there is a significant inhibition effect on S. aureus, E. coli, K. pneumoniae, and $P$. aeruginosa $(p<0.01)$. This result suggests that the inhibition halo is directly proportional to the increase in concentration of AgNPs. The statistical analysis showed that AgNPs have no significant effect $(p>0.01)$ on $S$. mutans and B. subtilis, promoting no inhibitory effect even at high Ag concentration.

Number of bacterial colonies inhibited by nanofibers with different AgNPs concentrations was quantified by dilution method and pouring in plate. Pure PCL nanofibers were 

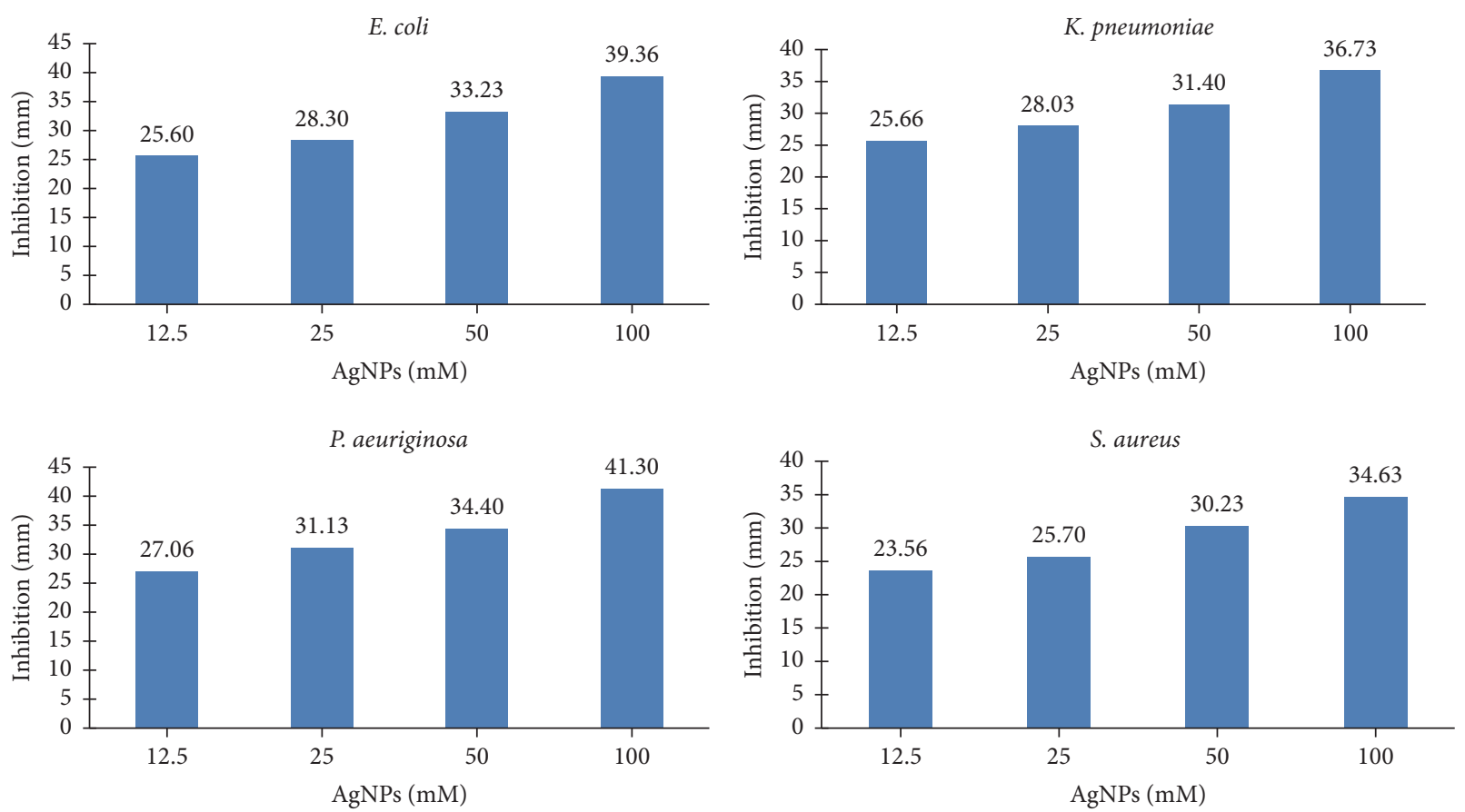

FIgURE 2: Antibacterial activity test of PCL-AgNPs at different concentrations.

TABLE 2: Kruskal-Wallis analysis using a 0.05 significance level.

\begin{tabular}{lccc}
\hline Bacteria & $p$ value & Df & $X^{2}$ \\
\hline S. aureus & 0.01556 & 3 & 10.3846 \\
P. aeruginosa & 0.01556 & 3 & 10.3846 \\
K. pneumoniae & 0.01556 & 3 & 10.3846 \\
E. coli & 0.01556 & 3 & 10.3846 \\
B. subtilis & N/A & 3 & N/A \\
S. mutans & N/A & 3 & N/A \\
\hline
\end{tabular}

used as control. Minimum inhibitory concentration (MIC) for $S$. aureus, E. coli, $P$. aeruginosa, and K. pneumoniae was $12.5 \mathrm{mM}$. As seen in Figures 3 and 4, S. aureus growth was inhibited $10.3 \%$ by the latter concentration, while $39.1 \%$ was inhibited by nanofibers with $100 \mathrm{mM}$ of AgNPs. E. coli growth inhibition was $27.2 \%(810,752 \mathrm{CFU} / \mathrm{mL})$ and $55.1 \%$ $(3,215,053 \mathrm{CFU} / \mathrm{mL})$ by nanofibers with 12.5 and $100 \mathrm{mM}$, respectively. $9.5 \%(580,953 \mathrm{CFU} / \mathrm{mL})$ of $P$. aeruginosa was inhibited by $12.5 \mathrm{mM}$ concentration. By contrast, $100 \mathrm{mM}$ inhibited $62.6 \%(3,812,536 \mathrm{CFU} / \mathrm{mL})$. K. pneumoniae inhibition was around $11.7 \%(648,421 \mathrm{CFU} / \mathrm{mL})$ and $42.8 \%$ $(2,397,192 \mathrm{CFU} / \mathrm{mL})$ by first and latter concentrations. Different from these bacteria, great inhibition was not observed for S. mutans and B. subtilis. Therefore, both microorganisms are not sensitive to those concentrations of AgNPs. These results agree with inhibition halos assay using SensiDiscs; both inhibition halo and MICs tests demonstrated a dose-dependent antimicrobial activity of PCL/Ag nanofibers
TABLE 3: Analysis of variance with 0.05 of significance level.

\begin{tabular}{lccc}
\hline Bacteria & Df & $F$ value & $\operatorname{Pr}(>F)$ \\
\hline S. aureus & 3 & 44.341 & $1.57 E-05$ \\
P. aeruginosa & 3 & 90.704 & $3.16 E-07$ \\
K. pneumoniae & 3 & 94.486 & $2.50 E-07$ \\
E. coli & 3 & 107.26 & $1.20 E-07$ \\
S. mutans & 3 & 2.9451 & 0.1099 \\
B. subtilis & 3 & 4.5252 & 0.05311 \\
\hline
\end{tabular}

promoting better antimicrobial effects on Gram-negative bacteria than Gram-positive strains.

Differences in colony inhibition were determined through an analysis of variance (ANOVA) with 0.05 of significance level, as shown in Table 3. Significant differences were demonstrated for E. coli, P. aeruginosa, K. pneumoniae, and $S$. aureus using nanofibers with either 12.5 or $100 \mathrm{mM}$ AgNPs. It was determined that an increase in silver concentration enhanced bacterial inhibition. Significant differences were not detected for S. mutans and B. subtilis, and these bacteria were not inhibited by any AgNPs concentration. Furthermore, a high correlation exists between inhibited colonies of E. coli, P. aeruginosa, K. pneumoniae, and S. aureus $(\mathrm{CFU} / \mathrm{mL})$ and $\mathrm{AgNPs}$ concentrations, as shown in Table 4 . On the contrary, such correlation was not observed for B. subtilis and S. mutans, supporting results from ANOVA test. Thus, bacterial inhibition also depends on AgNPs concentration. 

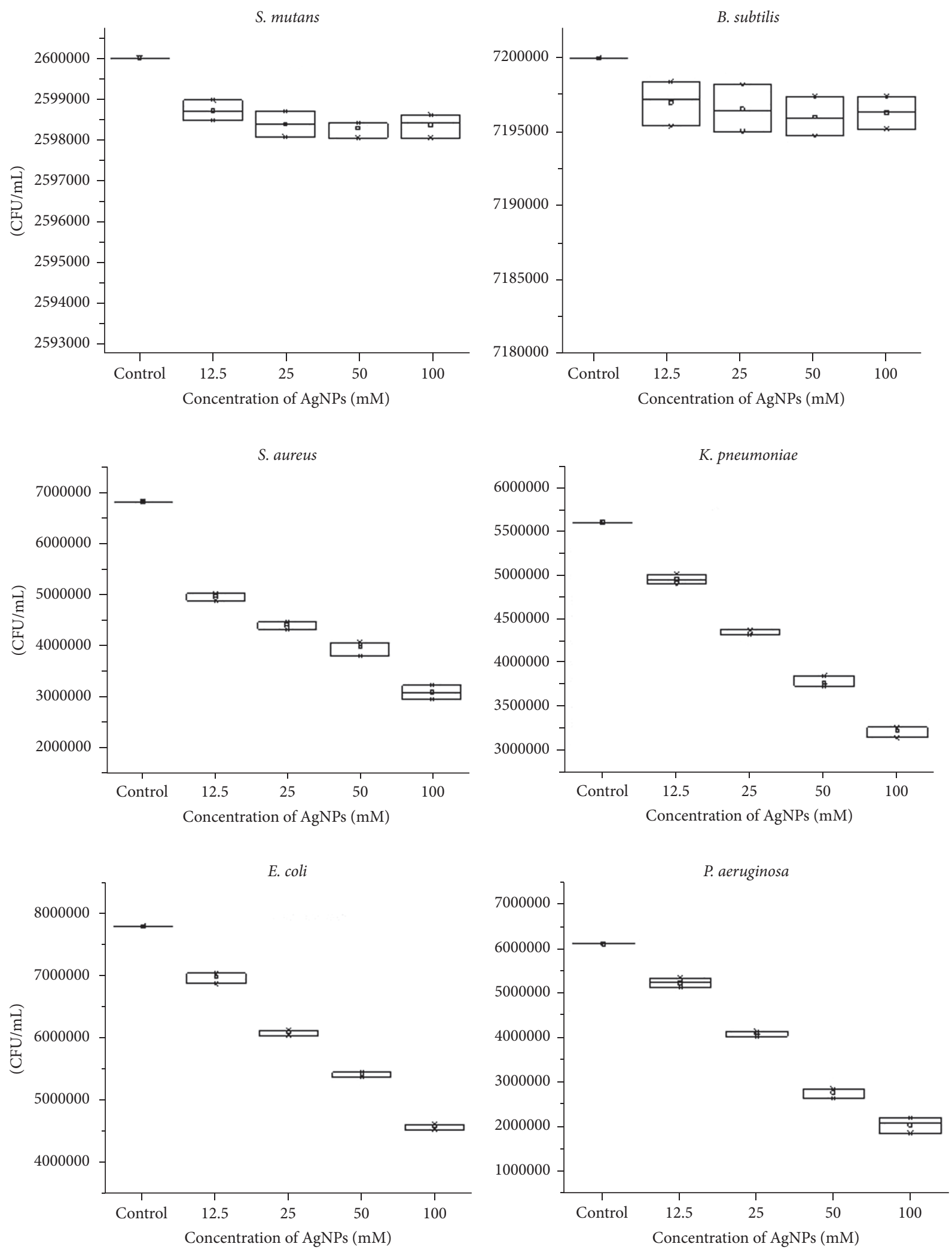

Figure 3: Colony forming units and inhibitory effect of PCL/Ag nanofibers at different concentration against S. mutans, B. subtilis, S. aureus, $K$. pneumoniae, E. coli, and $P$. aeruginosa. 

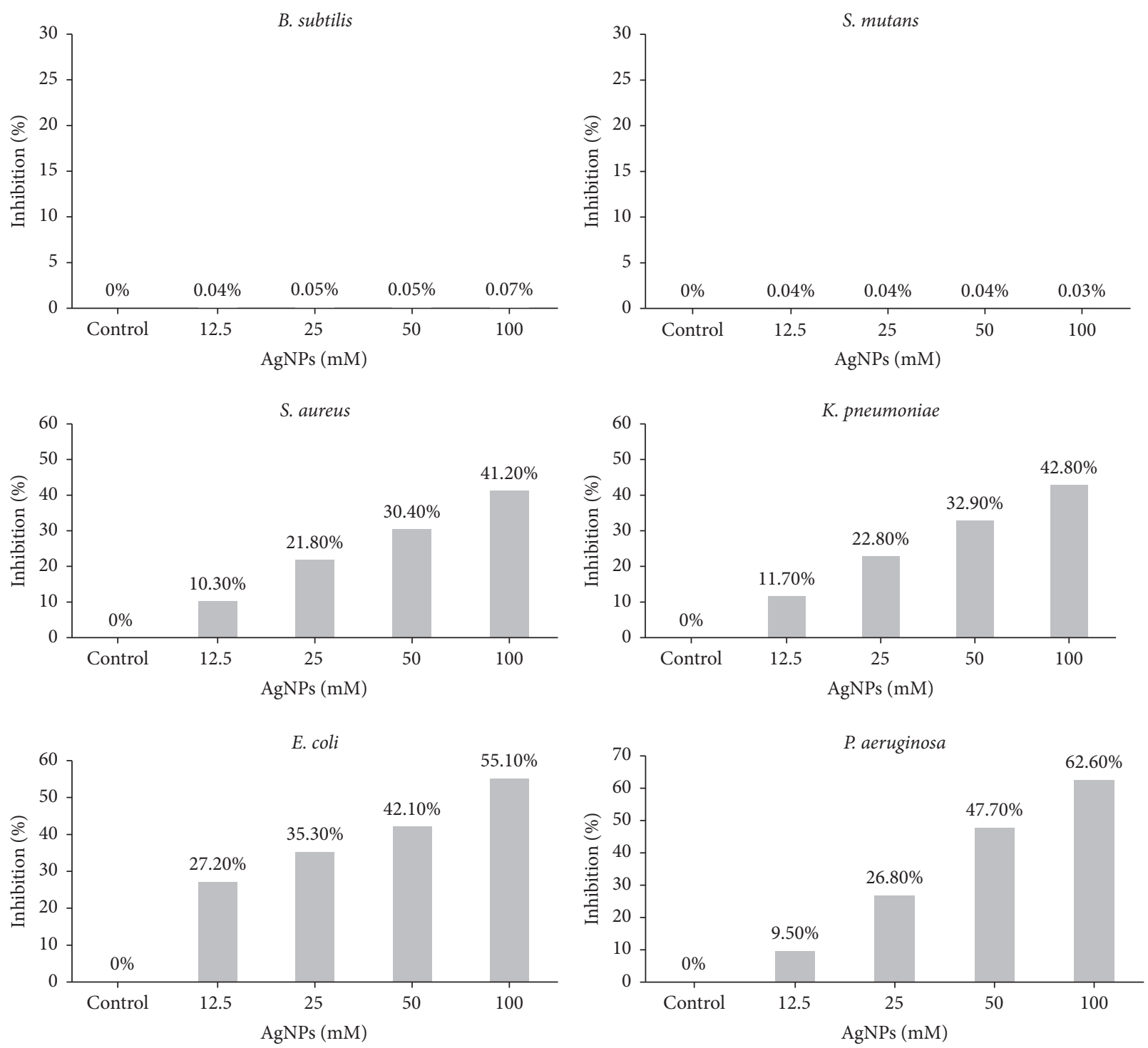

Figure 4: Bacterial inhibition percentage at different AgNps concentrations for B. subtilis, S. mutans, S. aureus, K. pneumoniae, E. coli, and P. aeruginosa.

TABLE 4: Correlation between inhibition halo and AgNPs concentration.

\begin{tabular}{lc}
\hline Bacteria & Correlation \\
\hline S. aureus & 0.9634 \\
E. coli & 0.9965 \\
K. pneumoniae & 0.9962 \\
P. aeruginosa & 0.9982
\end{tabular}

Both Kruskal-Wallis and ANOVA tests demonstrated that bacterial inhibition is directly related AgNPs concentration. However, specific response of each bacterium depended on their metabolic characteristics [10]. E. coli, P. aeruginosa, and K. pneumoniae are Gram-negative bacteria and their membranes present negative electrostatic charges, which attract and facilitate diffusion of AgNPs. Previous researches using $E$. coli strains have demonstrated that silver nanoparticles with size of $12 \mathrm{~nm}$ permeate through the membrane easily and interact with protein synthesis, causing structural changes and death [11]. P. aeruginosa is associated with nosocomial infections, so its inhibition is of great relevance [12]. $S$. aureus and $P$. aeruginosa are associated with skin infections caused by burns and postsurgery infections as well [13]. AgNPs have been reported to diminish adhesion capacity of this bacterium, preventing growth [14]. Similar to $S$. aureus and $P$. aeruginosa, PCL/Ag fibers inhibited growth of $K$. pneumoniae, although at a smaller amount. This bacterium generates capsule, so fiber effect was diminished. On the other hand, the inhibitory effect of PCL/Ag fibers was lower on Gram-positive bacteria. For example, S. aureus presented smaller inhibition halo and $\mathrm{CFU} / \mathrm{mL}$ than Gram-negative 
bacteria. This effect is associated with differences in cell wall composition, because peptidoglycan layer is thicker in $S$. aureus than other strains. Thus, diffusion was diminished $[11,15]$. In contrast, inhibitory effect on B. subtilis and $S$. mutans was minimal. According to literature [16], B. subtilis generates surfactants that reduce surface tension of medium and promote rapid growth and bacterial dissemination. S. mutans ferments sugars (mannitol and sorbitol), which stimulates adhesion to surfaces. Moreover, this bacterium bonds to other Streptococcus colonies and agglutinates by dextrans [17].

The main advantage of using smaller AgNPs $(<50 \mathrm{~nm})$ is their easy permeability through Gram-negative membranes. Furthermore, contact surface is bigger due to their small size. Incorporation of AgNPs into polymer matrices has been researched in order to obtain a prolonged bacterial inhibitory effect. Tran et al. [18] fabricated hydrophobic membranes composed of PCL and PCL/polyethylene glycol with AgNPs in weight percentages of $2.6 \%, 3.3 \%$, and $4.5 \%$, achieving a constant delivering for 28 days. Silver concentration in membranes was higher than the amount released. Inhibition effect on S. aureus was $29 \%$ using composite with $2.6 \%$ of silver, while $72 \%$ was inhibited with membrane with $4.5 \%$ of silver. On the other hand, no significant differences were detected for $P$. aeruginosa [15] which elaborated PCL and PCL/hydroxyapatite with $0.5 \%$ of AgNPs concentration. $E$. coli and S. aureus were inhibited, with halos of $2.21 \pm 0.14 \mathrm{~cm}^{2}$ and $1.66 \pm 0.02 \mathrm{~cm}^{2}$, respectively, demonstrating the higher sensitivity of Gram-negative bacteria towards AgNPs. It is important to remark that previous research reported in literature employed higher AgNPs concentrations than the values used in this work.

\section{Conclusions}

PCL/Ag fibers with diameters ranging from 834 to $634 \mathrm{~nm}$ were successfully obtained by electrospinning technique. Orientation, morphology, and diameter were influenced by the increment on AgNPs concentration. Bacterial growth was not affected by pure PCL fibers; however, the presence and concentration of AgNPs determined gradually the antimicrobial activity on the different bacterial strains, even in lower silver concentrations. Also, Gram-negative bacteria was demonstrated to be more sensitive PCL/Ag composites than Gram-positive strains determining a dose-dependent activity. PCL/Ag composites obtained by electrospinning technique was demonstrated to have a high potential for biomedical applications.

\section{Conflicts of Interest}

The authors declare that there are no conflicts of interest regarding the publication of this paper.

\section{Acknowledgments}

The authors gratefully acknowledge financial support by CONACYT and PROMEP. S. Reyes-López thanks Dr. Carlos Rodriguez for SEM images. They are grateful for the acceptance of this research in XXVI International Materials Research Congress (IMRC 2017).

\section{References}

[1] F. Fernández-Riverón, J. López-Hernández, L. M. PonceMartínez, and C. Machado-Betarte, "Resistencia bacteriana," Revista Cubana de Medicina Militar, vol. 32, pp. 44-48, 2003.

[2] J. López-Esparza, L. F. Espinosa-Cristóbal, A. DonohueCornejo, and S. Y. Reyes-López, "Antimicrobial activity of silver nanoparticles in polycaprolactone nanofibers against grampositive and gram-negative bacteria," Industrial \& Engineering Chemistry Research, vol. 55, no. 49, pp. 12532-12538, 2016.

[3] O. V. Salata, "Applications of nanoparticles in biology and medicine," Journal of Nanobiotechnology, vol. 2, no. 1, article 3, 2004.

[4] L. F. Espinosa-Cristóbal, G. A. Martínez-Castañón, R. E. Martínez-Martínez, J. P. Loyola-Rodríguez, J. F. Reyes-Macías, and F. Ruiz, "Antibacterial effect of silver nanoparticles against Streptococcus mutans," Materials Letters, vol. 63, no. 29, pp. 2603-2606, 2009.

[5] A. Panáček, L. Kvítek, and R. Prucek, "Silver colloid nanoparticles: synthesis, characterization, and their antibacterial activity," The Journal of Physical Chemistry B, vol. 110, no. 33, pp. 1624816253, 2006.

[6] R. Nirmala, H.-S. Kang, H.-M. Park, R. Navamathavan, I. S. Jeong, and H. Y. Kim, "Silver-loaded biomimetic hydroxyapatite grafted poly( $\varepsilon$-caprolactone) composite nanofibers: a cytotoxicity study," Journal of Biomedical Nanotechnology, vol. 8, no. 1, pp. 125-132, 2012.

[7] S. Y. Reyes-López, D. Cornejo-Monroy, and G. GonzálezGarcía, "A novel route for the preparation of gold nanoparticles in polycaprolactone nanofibers," Journal of Nanomaterials, vol. 2015, Article ID 485121, 7 pages, 2015.

[8] J. H. Roque-Ruiz, E. A. Cabrera-Ontiveros, J. Torres-Pérez, and S. Y. Reyes-López, "Preparation of PCL/Clay and PVA/Clay electrospun fibers for Cadmium $\left(\mathrm{Cd}^{+2}\right)$, Chromium $\left(\mathrm{Cr}^{+3}\right)$, Copper $\left(\mathrm{Cu}^{+2}\right)$ and Lead $\left(\mathrm{Pb}^{+2}\right)$ removal from water," Water, Air, \& Soil Pollution, vol. 227, no. 286, pp. 1-17, 2016.

[9] C. S. Ciobanu, S. L. Iconaru, M. C. Chifiriuc, A. Costescu, P. le Coustumer, and D. Predoi, "Synthesis and antimicrobial activity of silver-doped hydroxyapatite nanoparticles," BioMed Research International, vol. 2013, Article ID 916218, 10 pages, 2013.

[10] L. F. Espinosa-Cristóbal, G. A. Martínez-Castañón, J. P. LoyolaRodríguez et al., "Bovine serum albumin and chitosan coated silver nanoparticles and its antimicrobial activity against oral and nonoral bacteria," Journal of Nanomaterials, vol. 2015, Article ID 420853, 9 pages, 2015.

[11] I. Sondi and B. Salopek-Sondi, "Silver nanoparticles as antimicrobial agent: a case study on E. coli as a model for gramnegative bacteria," Journal of Colloid and Interface Science, vol. 275, no. 1, pp. 177-182, 2004.

[12] Y. Carmeli, N. Troillet, G. M. Eliopoulos, and M. H. Samore, "Emergence of antibiotic-resistant Pseudomonas aeruginosa: comparison of risks associated with different antipseudomonal agents," Antimicrobial Agents and Chemotherapy, vol. 43, no. 6, pp. 1379-1382, 1999.

[13] J. M. Pueyo, J. Barberán, P. L. Modejar et al., “Guía de tratamiento de la infección producida por Staphylococcus aureus resistente a meticilina," Revista Española De Quimioterapia, vol. 21, pp. 234-258, 2008. 
[14] M. D. P. Willcox, E. B. H. Hume, A. K. Vijay, and R. Petcavich, "Ability of silver-impregnated contact lenses to control microbial growth and colonisation," Journal of Optometry, vol. 3, no. 3, pp. 143-148, 2010.

[15] C.-H. Chen, S.-H. Chen, K. T. Shalumon, and J.-P. Chen, "Dual functional core-sheath electrospun hyaluronic acid/ polycaprolactone nanofibrous membranes embedded with silver nanoparticles for prevention of peritendinous adhesion," Acta Biomaterialia, vol. 26, pp. 225-235, 2015.

[16] T. E. Angelini, M. Roper, R. Kolter, D. A. Weitz, and M. P. Brenner, "Bacillus subtilis spreads by surfing on waves of surfactant," Proceedings of the National Acadamy of Sciences of the United States of America, vol. 106, no. 43, pp. 18109-18113, 2009.

[17] J. C. Ojeda-Garcés, E. Oviedo-García, and L. A. Salas, "Streptococcus mutans y caries dental," CES Odontología, vol. 26, pp. 44-56, 2013.

[18] P. A. Tran, D. M. Hocking, and A. J. O’Connor, "In situ formation of antimicrobial silver nanoparticles and the impregnation of hydrophobic polycaprolactone matrix for antimicrobial medical device applications," Materials Science and Engineering C: Materials for Biological Applications, vol. 47, pp. 63-69, 2015. 

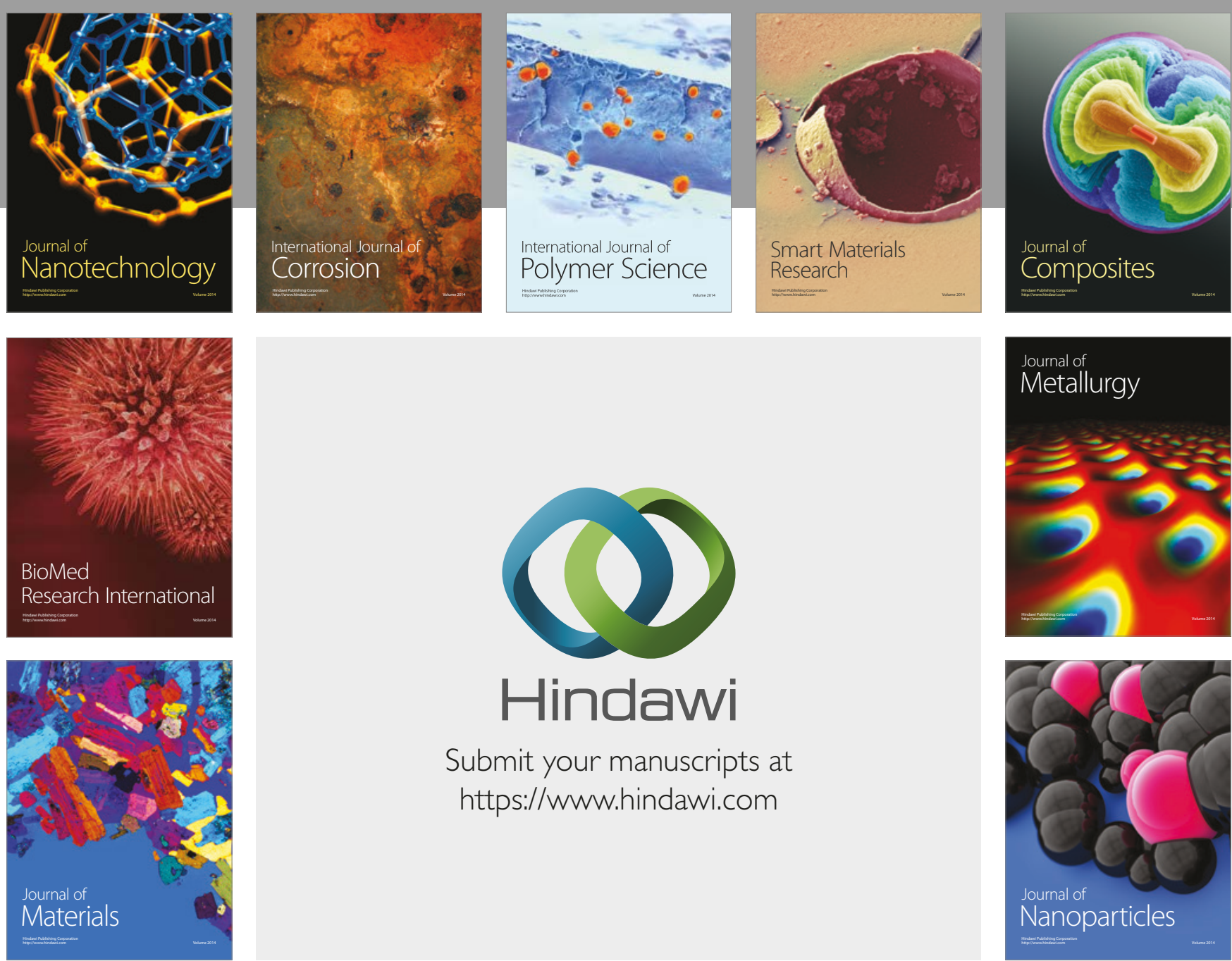

\section{Hindawi}

Submit your manuscripts at

https://www.hindawi.com
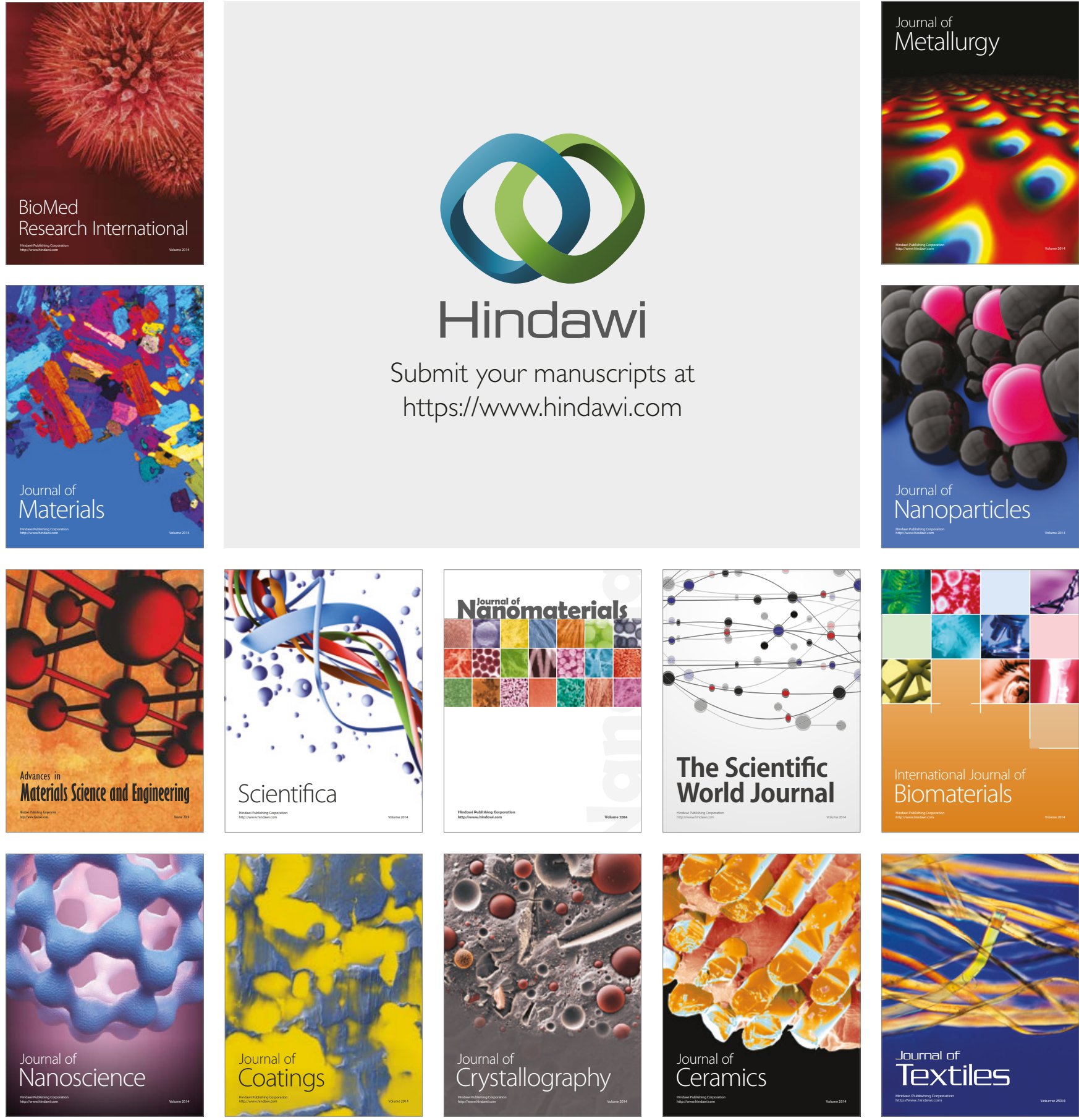

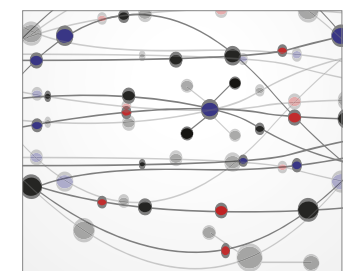

The Scientific World Journal
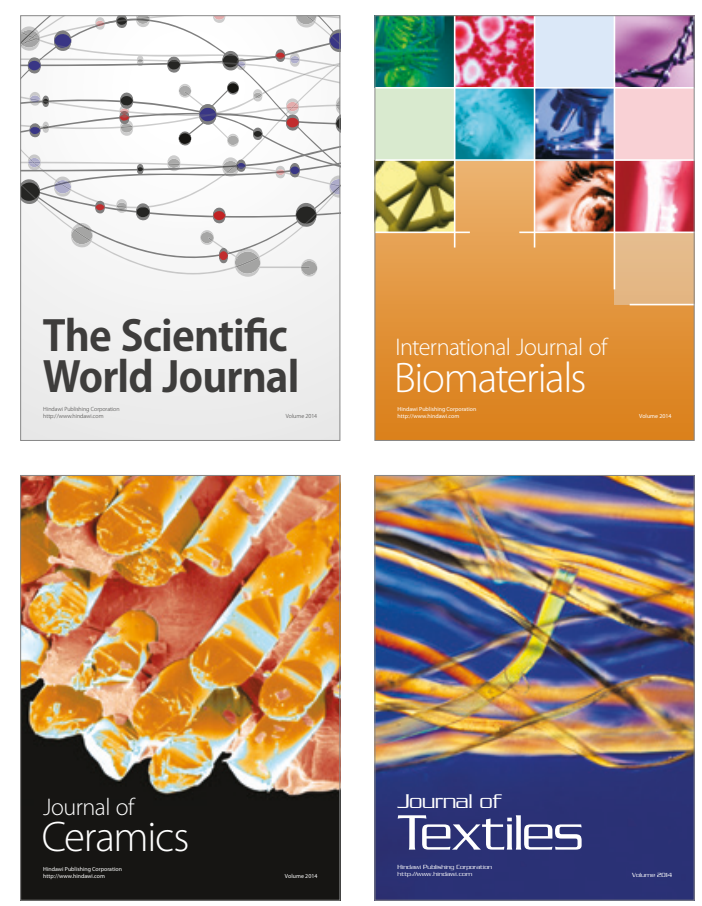